\title{
RESENHA
}

\section{O ELO DA INTERAÇÃO. INTERACTION AND SECOND LANGUAGE DEVELOPMENT: A VYGOTSKIAN PERSPECTIVE}

Book Review: Interaction and Second Language Development: a Vygotskian Perspective

RESUMO: Esta resenha aborda o livro de Rémi A. van Compernolle intitulado Interaction and Second Language Development: A Vygostkian Perspective cujo objetivo, segundo o autor, é estabelecer um elo entre dois nichos existentes na área de aquisição de segunda língua (L2) que tratam da interação, sendo eles: a abordagem cognitivo-interacionista (LONG, 1996; SWAIN, 1985) e a teoria sociocultural baseada nos pressupostos de Vygotsky (1978). Nesse contexto, a discussão proposta por van Compernolle tem como ponto de partida seu anseio em compreender os multifacetados processos envolvidos no aprendizado de L2 que ocorrem através da interação comunicativa.

PALAVRAS-CHAVE: Teoria sociocultural; Hipótese da interação; Aprendizagem de L2; Ensino de L2; Mediação.

O grande número de estudos baseados na teoria sociocultural (SCT, do inglês Sociocultural Theory) realizados no Brasil já havia sido documentado por Mainardes e Pino (2000). Esse aumento no número de pesquisas ancoradas na SCT no país, que começou por volta dos anos 80 estendendo-se até hoje, reflete um interesse mundial no trabalho do psicólogo russo Lev Vygotsky por pesquisadores/as interessados/as na aplicação de seus preceitos nas diversas áreas do ensino e aprendizagem. Como produto desse interesse, a editora John Benjamins, que publica a série Language Learning \& Language Teaching focada em questões práticas no campo da linguística aplicada, lançou em 2015 o volume 44 da série escrito por Rémi A. van Compernolle, Interaction and Second Language Development: A Vygostkian Perspective. Nessa obra, o autor aborda o papel da interação comunicativa no desenvolvimento de L2 pelo viés vigotskiano.

\footnotetext{
${ }^{1}$ Mestre em Inglês pela Universidade Federal de Santa Catarina. Agradeço a leitura crítica da versão inicial dessa resenha feita por Dra. Maria Rita Drumond Viana, Dra. Hanna Kivistö de Souza e avaliadores.
} 
REVIST A X, Curitiba, volume 13, n.2,p.144-147, 2018.

Baseado na atual conjuntura do ensino e aprendizagem de L2, na qual a tecnologia tem um papel cada vez mais relevante, van Compernolle tece um rápido panorama da pedagogia em L2 para contextualizar, no capítulo introdutório, seu nicho de estudo que é o papel da interação no desenvolvimento de L2, tendo como base a SCT e a abordagem cognitivo-interacionista (LONG, 1996; SWAIN, 1985). O objetivo do livro, segundo o autor, é unir esses dois olhares distintos sobre a interação em L2 através de uma visão 'branda' da SCT em relação ao desenvolvimento de L2 acoplada aos princípios metodológicos e a base empírica cognitivo-interacionista. Van Compernolle trata de forma didática e sucinta, já na introdução, as possíveis zonas de convergência das duas abordagens trabalhadas no livro. O livro está divido em 9 capítulos, uma análise crítica dos seus principais pontos é apresentada na sequência.

No segundo capítulo há uma breve exposição dos fundamentos que servem de base tanto para a SCT quanto para a perspectiva cognitivo-interacionista relacionados ao desenvolvimento de L2, sendo eles: os meios de mediação, a internalização e a zona de desenvolvimento proximal (ZPD em inglês) e a análise de micro-discurso. Com a escolha desses fundamentos, van Compernolle já sinaliza sua predileção em relação à SCT, uma vez que somente a análise de micro-discurso é de ordem cognitivointeracionista. Esse viés, mais vigotskiano, está presente em grande parte do livro.

O papel da comunicação para que o/a aprendiz de L2 venha a internalizar aspectos da linguagem através de atividade mediadas é central para van Compernolle. A fim de ilustrar esse fato, o autor traz exemplos de dados empíricos de suas pesquisas anteriores que demonstram os diversos impactos que um/a experiencedpeer pode proporcionar à produção oral do/a colega/aluno/a. É salutar a apresentação de diversos trechos de pesquisas que permeiam a obra pois elas não estão presentes apenas como um adendo ao conteúdo, há uma relação clara dos dados empíricos com os conceitos teóricos apresentados; bem como é positivo o fato dessa análise dos dados incorporar aspectos das duas abordagens trabalhadas no livro, algo que a própria Swain (SWAIN, 2013; SWAIN \& LAPKIN, 2013) tem buscado em seus trabalhos mais recentes.

A necessária discussão sobre o papel que o uso da língua materna (L1) pode vir a ter para o desenvolvimento da L2 é também abordada. $\mathrm{O}$ autor inicia essa reflexão partindo de posições contrárias ao uso da L1 em sala de aula - em certa medida ainda presentes em diversas abordagens de ensino de L2 - para então defender a otimização do uso de L1 em sala de aula em oposição ao seu total banimento. Van Compernolle defende o uso moderado de L1, especialmente em relação às mediações envolvendo 
metalinguagem, como uma ferramenta positiva, uma vez que pelo viés sociocultural “...ao barrar o uso da L1 efetivamente nega-se aos aprendizes o acesso ao mediador psicológico mais fundamental..." (VAN COMPERNOLLE, 2015, p. 91, tradução minha). Nesse contexto, a L1 não é vista como uma 'muleta' para a comunicação em L2, mas sim como um instrumento pedagógico para uso em determinados contextos para fins específicos. Esse tipo de reflexão é especialmente salutar para realidades onde todos/as ou a grande maioria dos/das aprendizes possuem a mesma L1.

Em relação à análise da participação e da recepção ativa. A mesma é compreendida como uma postura multifacetada, a noção de participação versus recepção extrapola a clássica visão dicotômica do agente ativo versus agente passivo; uma vez que visto pelo prisma da SCT, o processo de aprendizagem de L2 não é entendido como a mera recepção de insumo na língua alvo. Essa discussão é relevante pois não são raras as pesquisas da área que lidam com a análise de áudio apenas, e, por consequência, não possibilitam esse tipo de aprofundamento. Através das imagens de interações é ressaltado o papel da linguagem corporal na interação, nesse ponto o autor denomina como recepção ativa (quando a linguagem não é oral) a forma de interação quando o/a aluno/a recebe o insumo e demonstra que ele/ela estabeleceu uma relação de interação com o mesmo.

O autor também trata do conceito de avaliação dinâmica. Essa forma de avaliação é estabelecida quando são analisadas a capacidade individual (intrapessoal) e a capacidade individual assistida (interpessoal). A avaliação dinâmica é uma importante ferramenta pedagógica dentro da SCT pois, ao mesmo tempo, ela diagnostica a atual capacidade individual e fomenta o desenvolvimento futuro na L2. O autor argumenta que a avaliação dinâmica pode ocorrer tanto através de tarefas comunicativas quanto em testes de proficiência, em ambos os casos haverá um/a mediador/a que decidirá quando e como ocorrerá a assistência.

Um dos grandes diferenciais do livro em relação a similares da área é certamente a quantidade e variedade de exemplos provindos das pesquisas do autor e colaboradores que ilustram os diversos conceitos apresentados. Há inclusive, no website da editora, links de livre acesso às atividades de vídeos ${ }^{2}$ relatadas. No entanto, há um ponto a ser considerado, já que a maioria dos dados empíricos utilizados no livro referem-se somente a interações em pares ou pequenos grupos.

\footnotetext{
${ }^{2}$ Disponível em: <https://benjamins.com/\#catalog/books/lllt.44/video/1 >.
} 
REVIST A X, Curitiba, volume 13, n.2,p.144-147, 2018.

A linguagem do livro é acessível e instigante. Tendo em vista que o público alvo do livro é o/a aluno/a da graduação ou pós-graduação, o volume também traz perguntas e mais exemplos empíricos ao final de cada capítulo (exceto a introdução e conclusão); assim, o autor parece estabelecer uma leitura dialógica com seus leitores. Por focar em questões de ordem prática, o livro não adentra profundamente nos conceitos teóricos abordados, se isso pode ser considerado um ponto deficiente da obra a mesma não deixa de ser um ótimo ponto de partida para os/as interessados/as familiarizarem-se com o papel da interação no desenvolvimento de L2.

\section{REFERENCIAS}

LONG, M. H. The role of the linguistic environment in second language acquisition. In: RITCHIE, W. C., \& BAHTIA, T. K. (org.), Handbook of second language acquisition. New York: Academic Press, 1996.

MAINARDES, J.; PINO, A. Publicações brasileiras na perspectiva vigotskiana. Educação \& Sociedade, v. 21, n. 71, p. 255-269, 2000. Disponível em: $<\mathrm{http} / / / \mathrm{www}$. scielo.br/scielo.php?script=sci_arttext\&pid=S0101-73302000000200012 $\& \operatorname{lng}=$ en $\& n r m=i s o>$. Acesso em 08 jan. 2018. http://dx.doi.org/10.1590/S010173302000000200012 .

SWAIN, M. (1985). Communicative Competence: Some roles of Comprehensible Input and Comprehensible Output in its Development. In GASS, S. \& MADDEN, C. (org.), Input in second language acquisition. Rowley, MA: Newbury House, 1985.

SWAIN, M. The inseparability of cognition and emotion in second language learning. Language Teaching, v. 46 n.2, p. 195 - 207, 2013. DOI: 10.1017/S0261444811000486

SWAIN, M. LAPKIN, S. A Vygotskian sociocultural perspective on immersion education: The L1/L2 debate. Journal of Immersion and Content-Based Language Education, v. 1 n.1, p.101-129, 2013. DOI: 10.1075/jicb.1.1.05swa

VAN COMPERNOLLE, R.A. Interaction and Second Language Development: A Vygostkian Perspective. Philadelphia: John Benjamins Publishing Company, 2015. DOI: $10.1075 / 11 l t .44$

VYGOTSKY, L. S. Mind in society: The development of higher psychological processes (COLE, M. JOHN-STEINER, V. SCRIBNER, S. e SOUBERMAN, E., org.). Cambridge, Mass.: Harvard University Press, 1978. 